This item was submitted to Loughborough's Research Repository by the author.

Items in Figshare are protected by copyright, with all rights reserved, unless otherwise indicated.

\title{
Designing for video: investigating the contextual cues within viewing situations
}

PLEASE CITE THE PUBLISHED VERSION

http://dx.doi.org/10.1007/s00779-013-0702-y

\section{PUBLISHER}

(c) Springer-Verlag London

\section{VERSION}

AM (Accepted Manuscript)

\section{PUBLISHER STATEMENT}

This work is made available according to the conditions of the Creative Commons Attribution-NonCommercialNoDerivatives 4.0 International (CC BY-NC-ND 4.0) licence. Full details of this licence are available at: https://creativecommons.org/licenses/by-nc-nd/4.0/

\section{LICENCE}

CC BY-NC-ND 4.0

\section{REPOSITORY RECORD}

Mercer, Kevin, Andrew May, and Val Mitchell. 2019. "Designing for Video: Investigating the Contextual Cues Within Viewing Situations". figshare. https://hdl.handle.net/2134/23859. 


\title{
Designing for video: Investigating the contextual cues within viewing situations
}

\author{
Kevin Mercer, Andrew May*, Val Mitchel \\ Design School, Loughborough University, LE11 3TU, UK \\ *corresponding author: a.j.may@lboro.ac.uk
}

\begin{abstract}
The viewing of video increasingly occurs in a wide range of public and private environments via a range of static and mobile devices. The proliferation of content on demand and the diversity of the viewing situations means that delivery systems can play a key role in introducing audiences to contextually relevant content of interest whilst maximising the viewing experience for individual viewers. However for video delivery systems to do this they need to take into account the diversity of the situations where video is consumed, and the differing viewing experiences that users desire to create within them. This requires an ability to identify different contextual viewing situations as perceived by users.
\end{abstract}

This paper presents the results from a detailed, multi-method, user centred fi e Id study with 11 UK based users of video-based content. Following a review of the literature (to identify viewing situations of interest on which to focus), data collection was conducted comprising observation, diaries, interviews and selfcaptured video. Insights were gained into whether and how users choose to engage with content in different public and private spaces. The results identified and validated a set of contextual cues that characterise distinctive viewing situations. Four archetypical viewing situations were identified: 'quality time', 'opportunistic planning', 'sharing space but not content' and 'opportunistic self- indulgence'. These can be differentiated in terms of key contextual factors: solitary/shared experiences, public/private spaces, and temporal characteristics. The presence of clear contextual cues provides the opportunity for video delivery systems to better tailor content and format to the viewing situation or additionally augment video services through social media in order to provide specific experiences sensitive to both temporal and physical contexts.

Keywords: Video, contexts, personalisation, design

\section{Introduction}

The viewing of video increasingly occurs in a wide range of public and private environments, incorporating scheduled, stored, and streamed live video, which is accessed via a range of static and mobile devices. The proliferation of content on demand (including both professional and amateur sources), the growth of selfbroadcast and the diversity of the viewing situations means that delivery systems can play a key role in tailoring content and maximising the viewing experience for the individual. Different forms of personalised viewing have been supported in numerous real world systems (see $[1,2]$ as examples), however solutions in this arena are yet to fully take into account the true context of the viewing situation, which may have a major influence on the desired content and format of video. As an example the requirements for video, when being used as a social medium may be very different to more traditional viewing situations. 
In addition, the relevance of content (especially in the case of live broadcasts) may alter with changes in time, location or social setting. There is therefore a need to understand the situations in which video is viewed, and the contextual cues that help characterise and differentiate situations. The concepts of situatedness [3] and replace-ing space [4] demonstrate that higher level notions of social context could provide a general approach to the identification of aspects of a situation through which video-based experiences can be characterized.

The overall aim of this study was to investigate the situations in which individuals choose to interact with video. The specific objectives were to: (1) identify and verify the inter-contextual cues which influence the video user experience within common situations of use; and (2) determine the implications for systems that aim to provide personalised video across social, environmental and temporal contexts. The general approach taken was to conduct a literature review to identify inter-contextual cues documented within existing research literature. These were then augmented through a user centric study of consumption behaviours in order to both verify the existence of the cues identified from the literature and uncover novel contextual cues where possible. This study defines context as (only) that which is useful to convey and act upon [5]. In addition, the study approach is consistent with the argument of Bellotti and Edwards [6] that systems should not seek to act on behalf of the user, but should instead support a user's actions and defer to them in an efficient and non-obtrusive manner.

\section{Existing research - video viewing contexts}

Understanding user behaviour in given contexts has long been investigated as an approach towards improving personalised systems [7, 8, 9]. There are clear benefits to such a user centred approach, as though systems which employ high level user data tend to use low complexity modelling methods, they have demonstrated successful results when used under real world conditions [10]. User information has been found to improve the accuracy of personalisation systems when used as filtering criteria [11], and similar systems have been enhanced through the addition of models of high level contextual user activity [12].

Ethnographic study is one approach used both for the elicitation of user requirements for future television and video services [13] and more generally to improve our understanding of media consumption behaviours [14]. Previous field studies using this method both in the $\mathrm{HCl}$ and media studies literature have investigated content consumption via electronic devices (televisions, mobile devices, personal computers etc), and papers in this area form a rich source for the identification of specific accounts of use. From a review of the literature this study sought to identify verifiable detailed accounts of observed user behaviour. Many papers discuss the high level output of ethnographic study and naturally report findings in the context of their area of interest. However only in a minority of publications are rich written accounts of situated use provided, and it is these scenarios that permit further classification through the identification of cues within those viewing situations. A grounded theory analysis of the accounts was undertaken to develop an open coded list of criteria (inter- contextual cues) based on frequency of occurrence within the accounts and follow on discussion in the papers (see Table 1). The accounts in the literature were then re-analysed to identify consistently shared common criteria across accounts. When multiple occurrences were identified they were grouped into categories and "archetype" descriptive names assigned. The archetypes, and source literature, are summarised in Table 2. The focus of the review was social and work related contexts. Therefore use of video in educational contexts and public address information was excluded. Whilst the list of situations identified is by no means exhaustive, they do provide a representative snapshot of the majority of consumption situations and thus provide a basis for further study. 


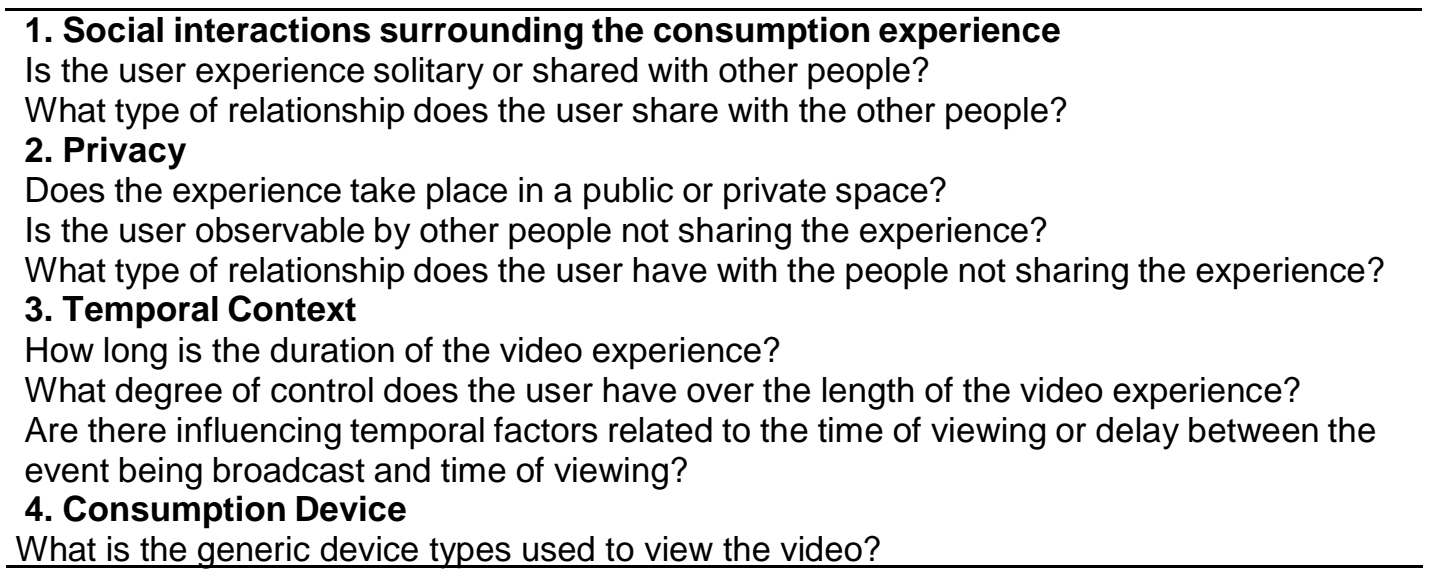

Table 1. Preliminary identification of inter-contextual criteria used to form the archetypes

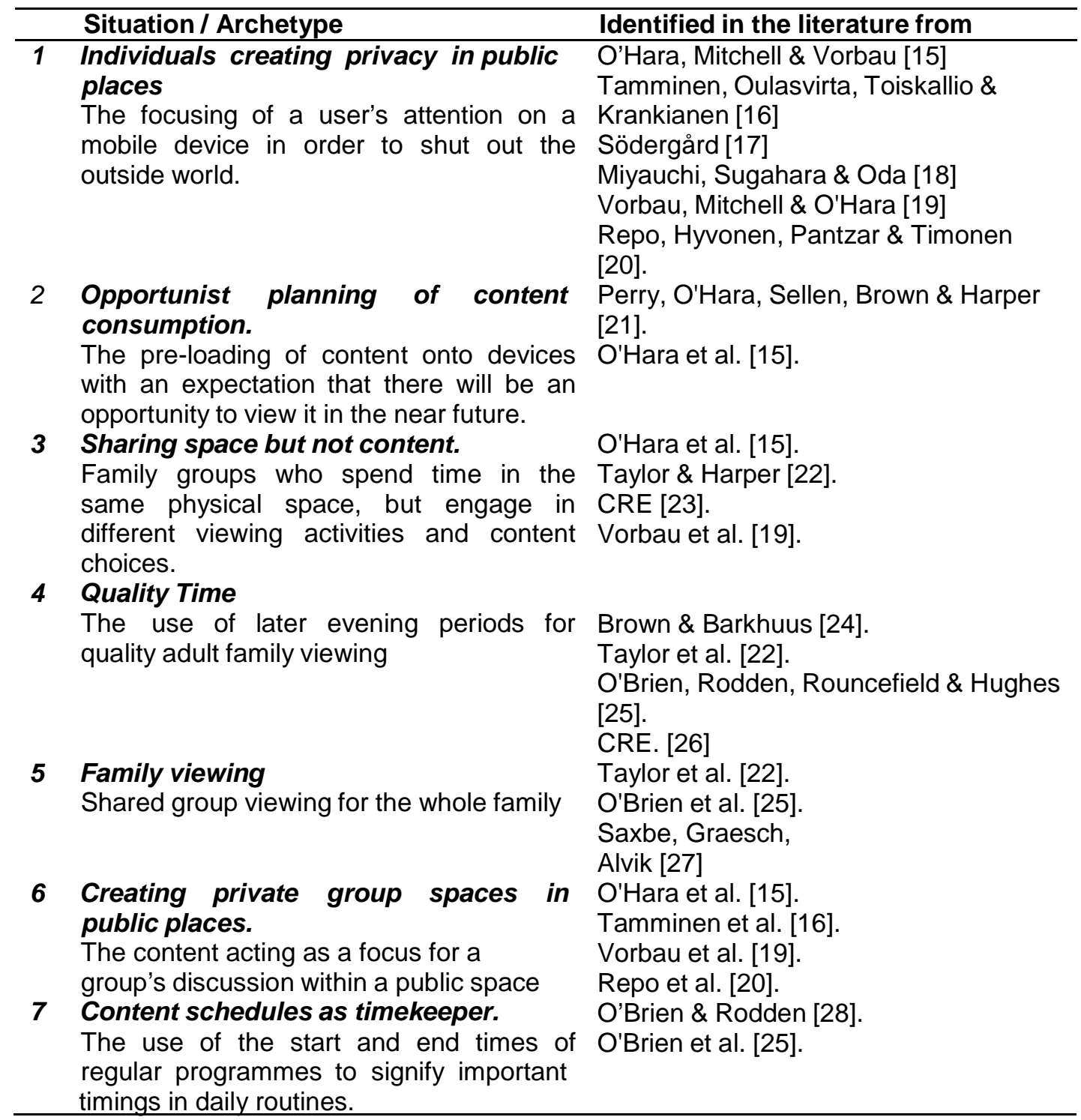

Table 2. Topology of identified archetype situations of use 
It was not feasible to validate all of the archetype situations of use identified from the literature through field study. Therefore to ensure a depth of coverage in the viewing situations of interest, a subset of archetypes were selected for further investigation based on:

- Diversity in inter-contextual cues between selected archetypes

- Maximised applicability to real world design

- Situations which are accessible to study

- Clear user benefits

Based on these criteria, three identified archetype situations from the topology were selected for inclusion within the study:

- Archetype 2. Opportunist planning of content consumption

- Archetype 3. Sharing space but not content

- Archetype 4. Quality time

As a whole, they represented diversity in the inter-contextual cues identified, as they each exhibited different surrounding social interactions, privacy issues, temporal contexts and consumption devices. They allowed for the opportunity of consumption of all types of content including live, scheduled, time-shifted and on-demand both from professional and user generated sources. They also cover very common contexts of use. It was hoped these archetype situations of use would allow the investigation of significant contextual based design problems currently facing developers of video consumption services which have significant implications for the user experience. At this point it could not yet be verified whether each of the criteria shown in Table 1 was a valid indicator of the particular situation, only that they were commonly shared features documented in the literature. An aim of the data collection component of this study was to validate the impact of each of these criteria and to identify new inter-contextual cues which may also be significant in relation to characterising the viewing situation.

\section{Method}

Eleven participants from the UK took part in the field study component of the research, seven male and four females, ranging in age from 24 to 47 . Users were primarily recruited through local community online bulletin boards and classified advertisements. Potential participants were screened using a short questionnaire to ensure that they were generally involved in the viewing situations of interest. All users owned a mobile phone capable of delivering video content and lived in homes with access to digital television broadcasts and a broadband Internet connection.

A mixed methods approach [29] was used within the study in order to capture externally observable information, and elicit insights from users. During the study each participant was interviewed twice. The aim was to accumulate authentic insights into people's experiences [30] over a period of time [31]. The first interview occurred during the initial kick off meeting. This interview focused on uncovering the user's general behaviours surrounding video content consumption. The second interview took place during the exit meeting approximately a week after the end of the two week data collection period. This interview was highly contextualised to each specific user. The interview provided further detail regarding situations either observed in the video footage or highlighted from the diary data. Both interviews used a semi-standardised approach conforming to the format described in Berg and Lawrence [32]. Interviews were recorded using a digital voice recorder and transcribed verbatim.

In order to capture externally observable cues, a range of observation methods were considered. These included direct observation by an experimenter, remote 
observation by camera, and self-capture by the participants themselves. The method eventually chosen was self-capture using a small mobile video camera. Although this reduces the control over data capture and is therefore susceptible to validity issues [33], it reduces experimenter effects [34], and the logistical and ethical issues to do with data capture. As O'Brien et al. [25] acknowledge, introducing a field worker into private environments for periods of extended observation can be problematic. Selfcapture using a small video camera is a recognised form of data capture within mobile contexts $[33,35,36]$. A small pilot study with three participants specifically incorporated both direct observation by the experimenter, and self-captured video. A comparison of the insights generated by each method showed that a wider coverage was obtained with self-captured video, although direct observation offered greater richness of data associated with viewing contexts. However, a key concern was the validity of the viewing contexts captured; as well as greater coverage, self-captured video increased confidence that the participant had not chosen to watch video due to the presence of the experimenter. For these reasons, self-captured video, rather than experimenter observation, was used within the main study.

All participants also kept a paper diary. This form of data collection is a long-standing methodology in human computer interaction research [37]. The procedure employed during the study followed the general approach to a diary method used by Carroll, Howard, Vetere, Peck \& Murphy [38], in that the goal was to create as far as possible a factual record of use. Participants were given a booklet to keep a record of all the video content they watched during the two week period of the study. Based on a page per day, the diary attempted to capture the following information for each viewing instance: Time and date; Content title; Broadcaster / Source; Duration; Watched with; Device watched on; Location or situation; and Any other comments.

At the end of the first week participants were telephoned or emailed to enquire about the data collection progress, as way of a motivational prompt. At the end of the data collection period the participants returned the diaries and the data was reviewed by the researcher in order to understand what had been collected. Approximately one week after the data collection the researcher met again with the participant in order to conduct the exit interview. At this time the participant was asked any questions that had arisen from analysis of the behaviours and situations recorded in the diaries in order to clarify any incongruity.

\section{Main findings}

The findings presented in this section represent the insights arising directly from the field study conducted by the authors during this research. A large amount of data of various types was collected and analysed:

- 6 transcripts generated from direct observation sessions (pilot study)

- 22 transcripts generated from entry and exit interviews.

- 63 video clips of video consumption situations generated by the participants.

- 363 instances of viewing from the diary data.

\subsection{New observed situation - solitary engaged viewing}

Analysis of the pilot observation data indicated that many video clips depicted examples of solitary private engaged viewing. The prevalence of these viewing situations had not been reported as a major viewing context within the literature which focuses primarily on the social interactions surrounding consumption $[22,24,25,39$, 40]. The behaviour observed during this field study builds on this prior literature and emerged perhaps due to use of self-reported video as a data capture method which allowed access to private spaces and 'alone time' situations such as consumption in participants' bedrooms. 
Unlike shared engaged experiences these solitary consumption sessions were much more opportunist in nature and tended to fit into the day when free time and opportunity allowed. An example from the video data was one participant who filmed themselves streaming a popular reality TV show ('The Apprentice') from the BBC iPlayer video on-demand service in their bedroom using a PC on a Saturday afternoon. They commented to the camera that on the occasions when they found some free time at the weekend they liked to catch up on scheduled content from the week which they might have missed - i.e. opportunistic consumption. A fuller posthoc analysis of the pilot revealed that solitary, engaged viewing in private situations accounted for a third of the viewing examples captured. As it fulfilled the original archetype selection criteria, a decision was taken to consider it explicitly within the main study data collection.

\subsection{Viewing of video inside the home}

\subsubsection{Most viewing occurred at home in the evening.}

Information from the diary data showed that the vast majority of viewing of any form of video by the participants (in fact over six times as much as any other) occurred in peoples' homes rather than outside in public or in work situations. This in turn affected the times when content was watched, especially during the working week. The diary information showed that half of all the reported video consumed during the study was done so in the evening after $7 \mathrm{pm}$.

\subsubsection{Early evening private viewing contexts were very social, lacked engagement with content and were based around set evening routines.}

Many video clips from participants depicted early evening viewing contexts with other members of the household present, typically focused on the TV. These tended to occur between $6 \mathrm{pm}$ and $8 \mathrm{pm}$ but precise timings depended upon an individual family's routine. In many cases food was either being eaten or cleared away.

Informal watching by the family group during evening meal times was reported as very common during the interviews. In both the video and directly observed situations family members were clearly not particularly engaged with the content. This context supports some of the paradigms also seen during the literature review of the home as a place where people can relax, be comfortable and close to other people [39] and also depicted the social use of television as a facilitator of communication [41].

\footnotetext{
"Yeah that's very common, it's like that nearly every night. One of us will be cooking and in and out of the living room. There is no door between the kitchen and the living room, so you can hear it (the content) anyway." Daniel 21
}

In most cases the action occurred in the living room in front of the main family television, though in other examples in the living room families were observed sat around laptop screens placed on coffee tables. An example was also captured in the dining room with a small portable TV on the sideboard. Invariably content consumed during this time consisted of scheduled live television broadcasts (including livestreamed content to laptops). There was a high percentage of news and light magazine type content consumed during these sessions.

\subsubsection{During the early evening families shared space but not necessarily content}

There were a number of examples from the video observation clips of families sharing space but not necessarily the same content. A typical situation was captured in one clip where the daughter of the family sat on the floor in the living room watching video clips from YouTube whilst the family TV was also on in the same 
room. This type of multi-tasking was very common with many examples of people surfing around casually consuming video content typically on laptops or mobile devices whilst other people watched live TV in the same room.

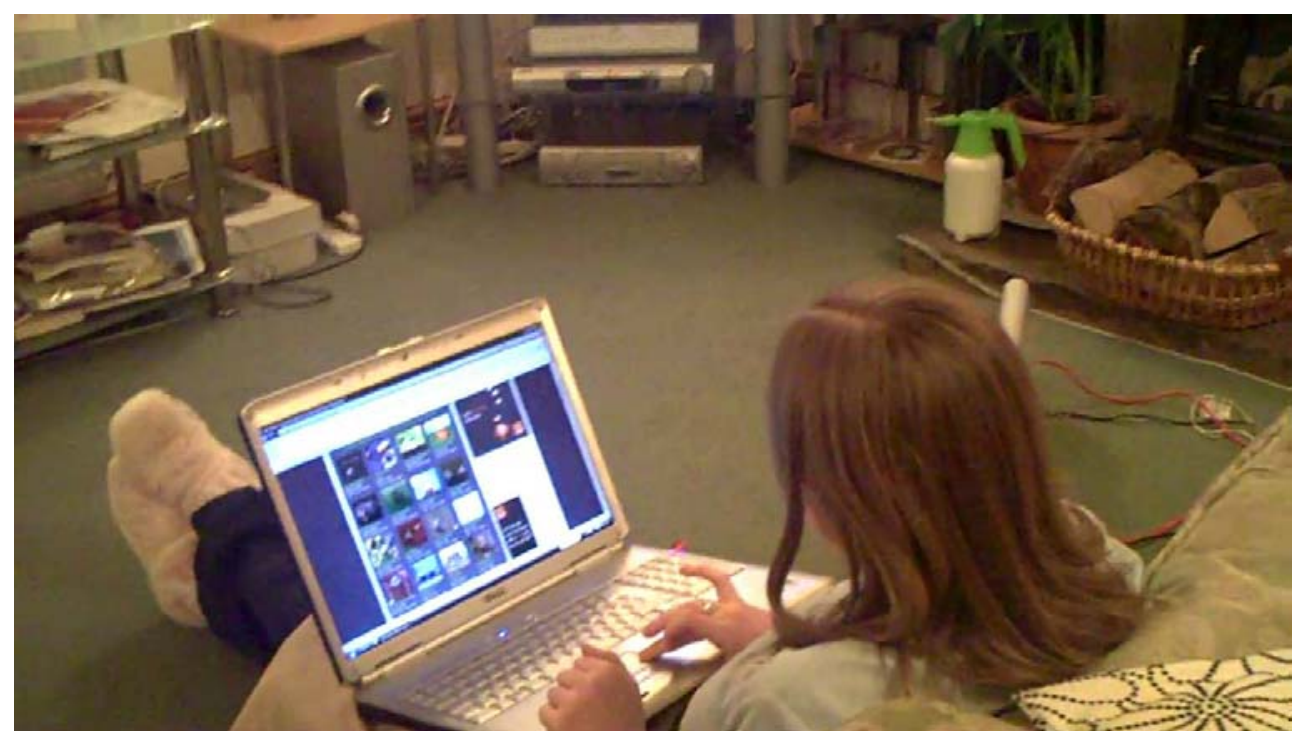

Fig. 1. Different content in the same space, the participant watches video in the living room on her laptop whilst other family members watch the main TV.

"...Paul will be watching the TV, and I will be talking to my sister on Gmail...so normally she will also be talking to four or five other people, so if you are just chatting to her, you might be waiting for a minute or more between each reply, so I watch YouTube videos whilst I'm waiting for her, then messaging her, and then waiting again. I'll watch half of it, pause it and go back...and I'll also have one eye on the TV at the same time." Esther 25

\subsubsection{With later evening viewing came greater planning and engagement with content....including significant use of video on demand}

There was evidence that less engaged early evening consumption evolved into more planned and engaged viewing as the night continued past $8 \mathrm{pm}$. One family reported that they had just watched the soaps during dinner, but were now going to watch some programmes they had "saved up" from over the Easter weekend. In both cases the participants knew exactly what they wanted to watch. This last example was also directly observed evidence of content being time shifted into peak viewing contexts for consumption on the main TV. There were also significant numbers of video on demand behaviours noted in diaries. In all $42 \%$ of all the content watched during the study was not watched in real time from a live TV schedule. This figure broke down as $11 \%$ of content time shifted and $31 \%$ originating as video on demand. Whilst recordable set top boxes where utilised in these situations, the study also captured users accessing content from the Internet using laptops and then connecting these to big screen televisions in the living room in order to view content on a larger screen. With planning also came greater involvement with content and considerations such as the ambiance of the consumption situation. Comfort, video quality and atmosphere all became important. There were examples captured on the video of people moving furniture and changing lighting in these situations to improve the environment. 


\subsubsection{Later planned viewing was much more highly engaged. Sharing these experiences seemed important}

Once 'planned-for content' was playing, users appeared to engage much more highly with it. Families typically said very little to each other during these viewing situations and were obviously engaged in the content. Despite the fact that much of the conversation stops during this period it was clear that sharing engaged viewing of this type with significant others was perceived as shared quality time. So whilst these situations had a social significance they were punctuated by a lack of communication between individuals. One of the example video clips showed a participant and their partner sat on the couch at home in a darkened front room. They explained in interview that they had been looking forward to the new episode of a popular series and had recorded it earlier when one of them was out so they could both sit down and watch it together. When questioned, the participant noted that it was important they watched the programme together as it would "spoil it if one of us had seen it first":

"I think it's important to do things together and one of the few things we will do together is sit down and watch TV or a video. We do go for walks but watching together is one of the main things.... I don't want to sit in front of the television watching rubbish, so sometimes I will plan specifically in advance to find something we will both want to watch." Kevin 47

\subsubsection{Though engaged evening viewing was primarily shared, in larger households people opted in or out at the start of the session.}

In all of the cases when engaged evening viewing was directly observed it was shared between groups of people. On the occasions when the social group does break up it creates opportunities for solitary but also still engaged viewing. These often occurred in areas of the house other then the living room, such as in bedrooms or conservatories. There were examples especially using streaming technology to seize on these situations in order to consume content of personal interest in an opportunist fashion. Examples of these behaviours were truly device agnostic with video clips and diary entries showing this type of behaviour occurring on TVs, computers and mobile devices. In all cases these were experiences in the home, in private situations, and opportunist in nature consisting of both live and on-demand content.

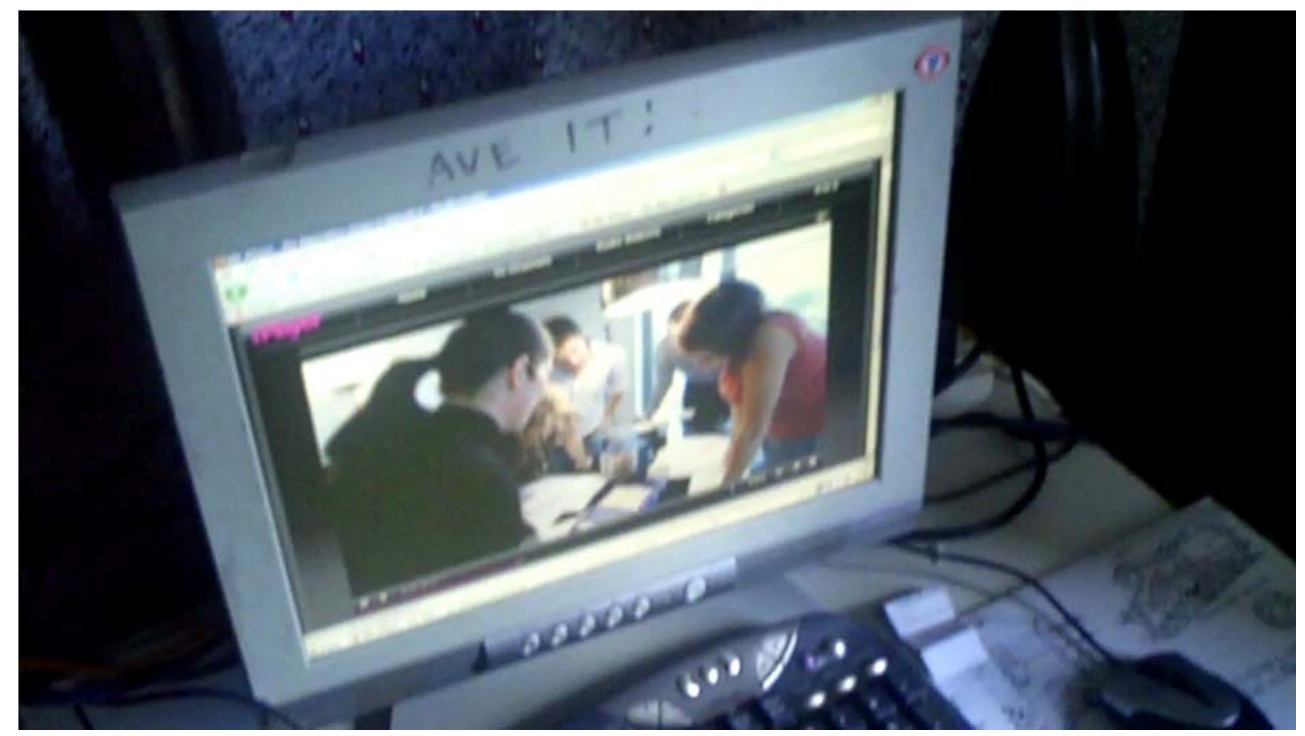

Fig. 2. Users were utilising streaming technologies across a range of devices to create engaging solitary consumption experiences when the opportunity arose. 
The diary data showed that this type of solitary engaged viewing made up over a third of all the video viewed by participants during the study. (In fact $51 \%$ of all the content viewed during the field study was done so alone.) For some users again comfort and video quality were mentioned as important. These seem significant factors whenever viewing is highly engaged, as this comment from a user consuming personal content from the Internet confirms.

"Whenever I get the opportunity I always go for the highest quality available. Even if it means at the start I have to wait for a few minutes for it to buffer up, I prefer good quality. I'm willing to trade that off." Phil 26.

\subsubsection{Planning around live or scheduled events created social situations.}

A further situation observed during the evening context was planning around content within social groups extending outside of the household. One participant reported regularly holding 'Soap and Sandwich' nights with her female friends. As with other early evening contexts these situations seemed very social, with the main actions and attention of the users focused around chatting and eating. Perhaps significantly these consumption examples were not time shifted but planned to be watched in real time.

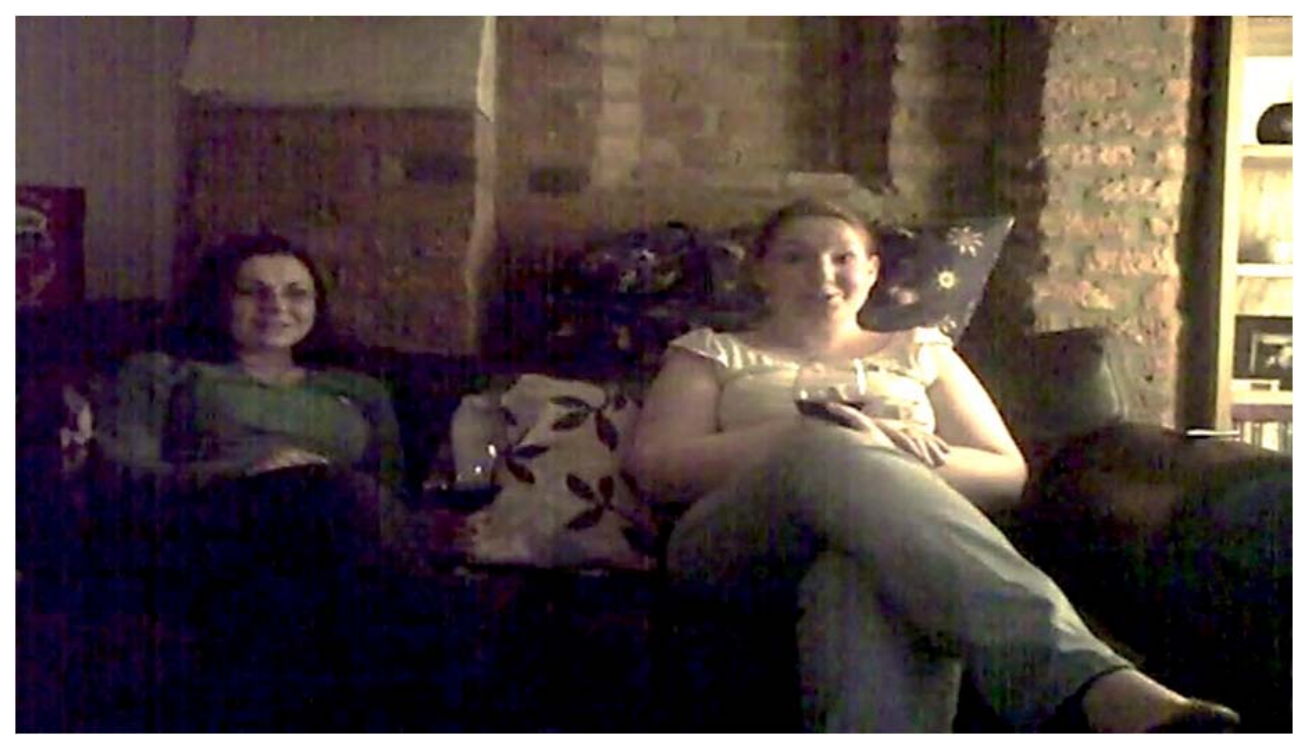

Fig. 3. Planned social situations surrounding content were surprisingly common, with people arranging specific social events to coincide with viewing schedules.

Sometimes socialising around content in this situation was done remotely. The study threw up two examples of this in the diary data which were later explored with the users in interview. The first example related to communication sparking video consumption. The participant was chatting to friends and family on instant messaging. These conversations triggered the sharing and consumption of related video clips to augment the discussion. The reverse example was seen during scheduled TV consumption when the themes of the content itself sparked the need to communicate and share with another person. In this example the user described swapping text messages in real time with a friend during a comedy chart countdown genre programme. This in turn led to the communication becoming part of the viewing experience itself.

"... a friend is dipping his toe into the world of stand-up comedy, he's done a few shows. He texted me to see if I was watching it, and I was, so it just kind of went back and forth, about who we thought he was the most like, and who should he try and be more like, it was fun...I would have probably given up and gone to bed if we hadn't been texting" Claire 28. 
What was clear in both cases was that the video content was an integral component to the social interaction. It was used both as a catalyst through which to initiate social activity and as a tool to augment and improve the flow of social dialogue during the exchanges. They also provided real world examples of the use of secondary screens for social augmentation of the viewing experience as discussed in the literature [40].

\subsection{Viewing of video outside the home}

4.3.1 The majority of viewing outside the home occurred in a small number of core situations.

Viewing video outside the home was identified and investigated in a number of different situations. However the general contexts in all but a few cases proved very similar. The major usage context was in work environments. On occasion this was related to work activities but most commonly it was during break times and lunch hours. The next most common mobile consumption situation surrounded travelling, with most examples relating to commuting on the train.

\footnotetext{
"Usually if I'm watching something outside the house it's when I'm travelling, like when I'm waiting in the airport or travelling by train or something, then I watch on my computer.....but that's because I have nothing else to do." Vaneni 26
}

Reasons for consumption in both these situations appear opportunistic. They represent a relationship between unplanned free time and access to devices which can deliver video content. Notably the ability to sit and be comfortable was again identified as an important component which adds further validation to previously identified factors in the literature around mobile video consumption [18] and considerations of mobility generally [42].

\subsubsection{Viewing on personal devices in public places is a solitary experience.}

Instances of viewing on personal devices observed during the pilot showed them to be relatively solitary experiences. In all direct observations the participant was in a public situation and viewed content alone. Only one participant reported examples of viewing video publicly with others on a personal device.

The nature of the solitary viewing experiences did not necessarily seem to be at the will of the participants. Rather users found themselves in situations where they did not know any of the people around them and so used interactions with their devices as a way to fill the void that would normally be filled by social interactions in such situations. The diary data was also indicative of these conclusions with only two recorded examples of consumption of content on mobile devices being shared when in a public environment, both from a single participant. This was to share usergenerated content on a mobile phone, which the creator had recently uploaded to YouTube. This was described as becoming the focus for the conversation and represented the only examples captured during the study of users sharing their own self-generated video content.

\subsubsection{Public viewing sessions on personal devices was highly constrained by temporal factors.}

There was evidence of situations often controlling the viewing experiences in public contexts rather than the other way around. For example, participants travelling on the train were highly constrained by time. Though the duration of the viewing experiences varied, video clips were often cut short by the situation (usually by the arrival of the train at the participant's station). Evidence of dipping in and out of mobile content was also observed in the context of keeping up to date with live sporting and news events. The diary information revealed that the duration of viewing 
situations which occurred in public were significantly shorter in length than private ones. Only one public mobile viewing session (using a personal device) captured in the diary data lasted longer than sixty minutes.

\subsubsection{Public viewing of live events created opportunities for socialness and community.}

Four of the participants captured instances of viewing live sporting events in public group situations. These occurred in pubs and bars and on large screen televisions in the venue rather than on mobile devices. These examples were the only public viewing situations captured which depicted sustained social interaction. The content created discussion both within the group of friends the participant was watching with and also between those groups and other people in the venue. From the interview data the motivations for watching live sport in this situation were twofold. Firstly the motivation was economic. The content was premium and as such would be very costly to subscribe to at home. Secondly participants enjoyed the atmosphere of watching in a group and felt the social element added significantly to the experience of watching, thus enhancing the viewing experience with a social one.

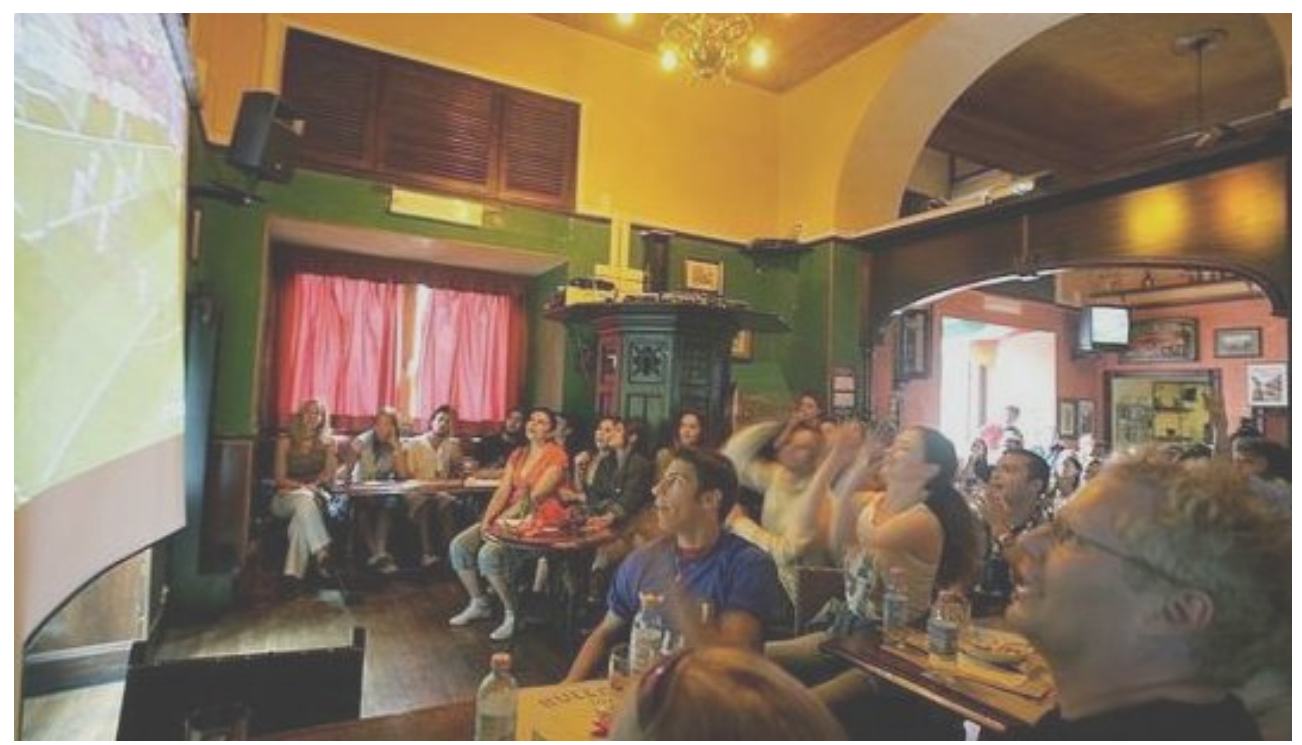

Fig. 4. Group viewing of live sporting events created opportunities for socialness.

\subsubsection{Content choices on mobile devices are restricted by a number of factors.}

The observation sessions, (both direct and through video) yielded examples of content choices outside of the home being constrained, primarily due to the current viewing situation, but also because of other constraints including mobile connection availability as well as access to premium content. The study found that laptops were the preferred option for video consumption in mobile environments amongst study participants with $70 \%$ of all viewing outside the home taking place on a laptop. Convenient and opportunist access to content through the Internet made use easier than mobile telephones and other media players. Financial factors were also a significant barrier to both content choice and uptake of video consumption via mobile phones, including monthly subscription costs, and mobile data tariffs.

\subsubsection{Mobile public viewing was full of distractions and users lacked engagement} with the content.

The mobile environments observed during the study undoubtedly had louder background noise levels than private ones, but this served more as a minor 
distraction rather than a real impairment to the viewing situation. There were also a number of instances of participants choosing to wear headphones whilst watching in these situations. More important issues appeared to be visual distractions in the environment and specific auditory events which attracted the viewer's attention; these included visual distractions during train journeys, public announcements, and general movement of others in the vicinity. These disruptions manifest themselves in the form of the user momentarily glancing away from the screen and in some cases turning around to see what was happening.

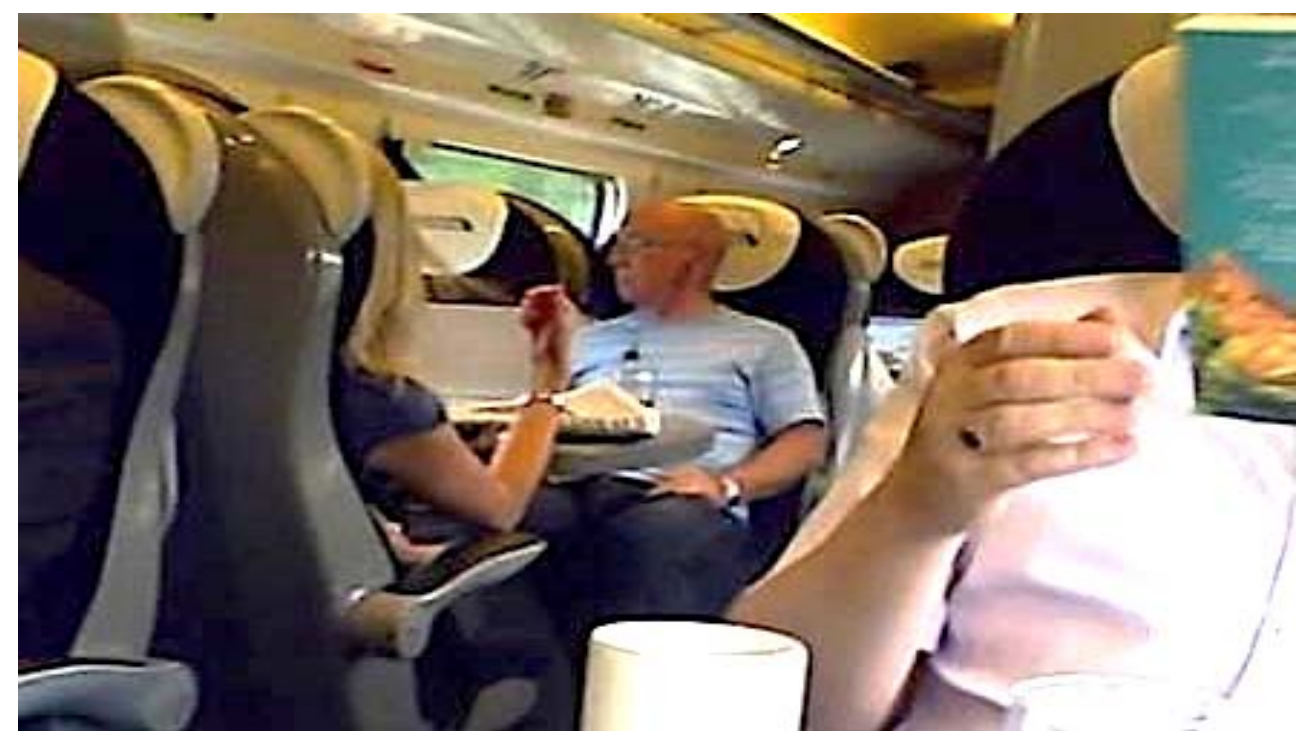

Fig. 5. A distracted user watching iPlayer on the train turns away from his laptop screen to look out of the window.

Interestingly the users themselves seemed to create their own distractions. These included continually checking the time, eating and checking their mobile phone for new messages. It appeared that in these settings users wished to remain aware of the situation around them and were not overtly seeking to become engrossed in the video content they were consuming.

\subsection{Summary of findings}

The dominant contextual factor apparent during the field study which defined engaged and non-engaged viewing was whether the environment was public or private. Engagement is significant as Taylor and Harper [22] showed that the level of engagement with video content was central to understanding people's motivations for watching. An example of unengaged viewing would be when people watch in a group just to participate in the social interactions around daily family routines. Content choice is largely unimportant. Engaged viewing occurs when users seek out specific content of personal interest in order to create absorbing viewing experiences. In addition, the following findings were also noted from the field study:

- Numerous instances were observed of users themselves, actively attempting to remain highly aware of their current surroundings rather than trying to block distraction out.

- Viewing quality and perceived comfort were important for users in terms of engaging with content.

- Rather than screen size or device mobility, convenient and cheap access to content appeared the main influencing factors in consumption device selection. 
- Within private personal spaces both temporal and social factors appear key contextual indicators.

- The move from highly social, light and unengaged viewing into later, planned and highly engaged viewing was prominent and predictable in all the households observed during the study. This agrees with the findings in [22].

- There was a significant shift away from scheduled content towards stored and streamed video which was either time-shifted or accessed on demand.

- Consumption of user-originated content represented a tiny fraction of the content consumed across all contexts when compared to professionally produced sources (less than $1 \%$ of the viewing captured in the diaries).

- Live and scheduled content retained relevance for participants when creating and facilitating social events, both planned around the content and formulated in an impromptu fashion due to the shared viewing environment.

- The TV in the living room remains the key focus for sharing content.

Perhaps the most surprising finding was that there was a large amount of solitary engaged viewing of video occurring at home. Based upon the low amount of discussion of this situation in the literature, this would appear to be a relatively new phenomena, most likely fuelled by the numerous alternative routes into video content that now compete with the traditional television.

\section{Validation of contextual cues that define viewing situations}

\section{1 'Quality time'}

The literature identifies a key viewing situation within families relating to enjoying viewing together after the time when children have gone to bed. This situation was indeed identified on numerous occasions in the data collected during the study. Examples were identified in both the video and direct observation data. Coding of information collected from the diary study also identified 57 reported instances of viewing within this situation (16\% of all examples). The hypothesised and validated cues are shown in Table 3.

\begin{tabular}{lll}
\hline Hypothesised cues from literature & Validated & Comments \\
\hline $\begin{array}{l}\text { The user experience occurs in a } \\
\text { shared private space. [22, 25, 26] }\end{array}$ & Yes & $\begin{array}{l}\text { Invariably in the comfort of the } \\
\text { living room. }\end{array}$ \\
$\begin{array}{l}\text { The experience is shared with adult } \\
\text { family members. [22, 25, 26] }\end{array}$ & Yes & $\begin{array}{l}\text { By couples and other closely } \\
\text { associated social groups, such as } \\
\text { housemates and friends. }\end{array}$ \\
$\begin{array}{l}\text { The user is not observable by anyone } \\
\text { not sharing the consumption } \\
\text { experience. [25] }\end{array}$ & Yes & $\begin{array}{l}\text { Householders not wanting to } \\
\text { share the experience remove } \\
\text { themselves from the environment. }\end{array}$
\end{tabular}

The consumption experience is long Yes \& Refined (over half an hour). [24, 26]
Can consist of a single or stacked number of content items. Time shifted, and on-demand content is common, as is planning. Occurs in the evening after dinner.

The consumption experience ends when the content finishes.
The user has control over the length of Yes the experience. [24, 25]

The users utilise the main family television. [22, 25]
Yes

Users do use the main TV for consumption, but utilise a range of sources to obtain and access content. 


\section{2 'Opportunist planning'}

This archetype identifies behaviours of individuals who are described in the literature as pre-loading content on to their mobile devices in the expectation that an opportunity to view it will present itself in the near future. Users are reported as engaging in a form of loose planning so that content of interest is available when they next find themselves in a situation where they need to kill time. Through there were not a great number of examples, (only ten recorded in the diary data representing 3\% of all examples) this consumption situation was also reported as everyday user behaviour during the interviews by a number of participants.

During the study users did indeed load content onto their mobile devices, but this did not limit viewing only to public situations. Therefore the example in the literature from O'Hara et al. [15] which describes users time shifting content into contexts outside the home might not necessarily be based on a motivation to free up time spent watching in the home; rather it may just be the case that users wish to maximise the possibility to watch things matching their preferences whenever the opportunities arise.

The contextual cues below refer to the viewing of video in public situations; private opportunist viewing is considered through the formation of a new individually characterised viewing situation ('opportunist self-indulgence').

\begin{tabular}{|c|c|c|}
\hline Hypothesised cues from literature & Validated & Comments \\
\hline $\begin{array}{l}\text { The user experience is solitary. } \\
{[15,21]}\end{array}$ & Yes & Viewing is not shared. \\
\hline $\begin{array}{l}\text { The experience occurs in a shared } \\
\text { public space. [15] }\end{array}$ & Yes & \\
\hline $\begin{array}{l}\text { The user is observable by strangers } \\
\text { not sharing the experience. [15] }\end{array}$ & Yes & $\begin{array}{l}\text { People around the viewer can often } \\
\text { see the screen. }\end{array}$ \\
\hline $\begin{array}{l}\text { The consumption experience is longer } \\
\text { than for Archetype one (creating } \\
\text { privacy in public places). [15] }\end{array}$ & Partly & $\begin{array}{l}\text { The prospective consumption } \\
\text { experience needs to be long enough } \\
\text { to offer a likely opportunity to } \\
\text { consume content of interest. }\end{array}$ \\
\hline $\begin{array}{l}\text { The user has little control over the } \\
\text { length of the experience but visibility } \\
\text { of the prospective duration. }[15,21]\end{array}$ & $\begin{array}{l}\text { Yes \& } \\
\text { Refined }\end{array}$ & $\begin{array}{l}\text { The user makes an estimation of } \\
\text { the likely available time, however } \\
\text { has little control over the length or } \\
\text { end point of the experience. }\end{array}$ \\
\hline $\begin{array}{l}\text { The user utilises a mobile device such } \\
\text { as a telephone, media player or laptop. } \\
{[15,21]}\end{array}$ & Yes & \\
\hline
\end{tabular}

Table 4. Hypothesised and validated cues for 'opportunistic planning' in public situations

5.3 Validating the contextual cues of 'sharing space but not content' This archetype describes family groups who spend time in the same physical spaces as each other but who engage in different consumption activities and content 
choices. A study by Vorbau et al. [19] identified an extension to this activity through the use of mobile products as secondary consumption devices in the same social spaces. This situation was identified within the study on numerous occasions, and most strikingly through the video and direct observations. In all, 25 instances were also identified from within the diary data, ( $7 \%$ of examples).

Evidence for the cues to this situation were apparent within the study data, although the reality of the noted situations appeared much more highly focused upon sharing social spaces than consuming content. In reality the users who did not share the key viewing experience actually carried out a myriad of parallel activities including chatting, reading, eating and surfing the Internet. In addition the boundaries between inclusion and exclusion from the viewing experience were much greyer than may have been initially envisaged from the literature. The experiences themselves also appeared generally less engaged for all users with parallel activities such as eating or tidying up commonly reported or observed. 15, 19, 22, 23

\begin{tabular}{lll}
\hline Hypothesised cues from literature & Validated & Comments \\
\hline $\begin{array}{l}\text { The user experience may or may not } \\
\text { be shared, (depending upon the } \\
\text { number and focus of family members } \\
\text { present). [15, 22, 26] }\end{array}$ & Yes & \\
$\begin{array}{l}\text { The experience occurs in a shared } \\
\text { private space. [15, 22, 26] }\end{array}$ & Yes & $\begin{array}{l}\text { Usually with family members using } \\
\text { other devices in front of the family } \\
\text { television. }\end{array}$ \\
$\begin{array}{l}\text { The user is observable by family } \\
\text { members not sharing the consumption } \\
\text { experience. [15, 22] }\end{array}$ & $\begin{array}{l}\text { Yes \& } \\
\text { Refined }\end{array}$ & $\begin{array}{l}\text { The user is observable by family and } \\
\text { friends who are likely to each present } \\
\text { different levels of engagement with the } \\
\text { content. }\end{array}$ \\
$\begin{array}{l}\text { The consumption experience is long } \\
\text { (over half an hour). [22, 26] }\end{array}$ & $\begin{array}{l}\text { Yes \& } \\
\text { Refined }\end{array}$ & $\begin{array}{l}\text { The consumption experience tends to } \\
\text { occur in snacks of half hour shows. }\end{array}$ \\
$\begin{array}{l}\text { The user has control over the length of } \\
\text { the experience. [22] }\end{array}$ & Yes & $\begin{array}{l}\text { The consumption experience ends } \\
\text { when the content finishes. }\end{array}$ \\
$\begin{array}{l}\text { The users utilise both mobile devices } \\
\text { such as telephones, media players } \\
\text { and laptop as well as the family } \\
\text { television in parallel. [15, 19, 22, 26] }\end{array}$ & Yes & \\
\hline
\end{tabular}

Table 5. Hypothesised and validated cues for 'sharing space but not content'

\subsection{Discovery and validation of opportunist self-indulgence}

This is a new situation which was identified initially from the diary data collected during the pilot study, as described in section 4.1. This situation, termed 'opportunist self-indulgence', sees individual users taking opportunities as they arise to consume personal content of real interest just to themselves. The diary data also recorded a high amount of on-demand consumption in these situations from PVRs and streaming video websites such as BBC iPlayer, YouTube, Sky and Channel Four's 4oD. Perhaps significantly this situation was not seen in the literature, but plannedfor viewing through downloading content to devices was. In reality this study identified many more examples of opportunist self-indulgence than opportunist planning. The lack of download behaviours in the study data may suggest that since this situation was explored in [19], user behaviours may have moved on in step with improvements in device performance and access to streamed content.

These contexts are identified as opportunist as they can happen at different times of the day and on many different devices, therefore the timing of the experience is 
unplanned. During interview, users themselves identified these situations as significant. Examples from the study included a participant taking the opportunity to watch a favourite recorded programme on arriving home early from work before the other members of the household got home, and someone watching an episode of a programme downloaded to their iPod in bed whilst their partner slept. This situation covered many different locational, device and temporal contexts. In all cases the consumption was solitary, engaged in nature and conducted within a private viewing situation. As such this situation covered (amongst others) the second component of the opportunist planning archetype discussed earlier in this section. In all $35 \%$ of the total number of instances of consumption captured through the diary study were categorised under this situation.

Validated cues post study

The user experience is solitary.

The experience occurs in a private space, usually in the home.

The experience is not observed by others.

The user utilises any devices available to them such as a mobile telephone, media

player, laptop computers as well as the family televisions.

Table 6. Validated cues for 'opportunistic self-indulgence'

\section{Implications for streamed video providers}

\subsection{Supporting the four key viewing situations}

This study has been able to identify four key consumption situations and validate the presence of inter-contextual cues at play within each that can be used to differentiate between viewing situations. Understanding which viewing situation the user is currently within is of real benefit for future system design as it allows both optimisation of preferences collection and optimisation of the experience as content is streamed to the user. A system could identify key contextual cues either through implicit inference or explicit user facing strategies, and from these determine the viewing situation. Based on the findings of this study the authors advocate that the following factors are used to differentiate viewing situations:

- The division of private and public spaces

- Whether the experience is solitary or social

- Temporal information

\subsection{The division of public and private.}

Throughout the study the division of viewing situations occurring either within a public or private space has appeared a key factor in understanding the levels of engagement a user is drawn into during the viewing experience. It may be the case that users in busy public environments simply do not wish to switch off their attention from the world around them and give it over to watching video in the same way as we do when we are highly engaged in content at home. Users appear to need a safe harbour in terms of a relaxed and socially unthreatening environment to allow them to make that step, including the perception of comfort. In the vast majority of cases this was only achieved in the user's home. Identifying this key contextual cue could allow a clear and useful division in the viewing experiences for users which can be exploited by future systems, and through simple well understood solutions such as identifying the home wireless network, streaming video solutions can easily identify this powerful contextual indicator.

\subsection{Solitary or social.}

Whether the experience is shared or solitary appears a clear indicator as to the nature of the viewing situation the user is engaged within. Two of the four key 
consumption contexts investigated and verified were directly related to social aspects and the sharing of both space and the experience. Identifying this fact would again assist greatly in paring down the context to one of the four viewing situations. In relation to social media there were examples of its use to augment solitary viewing experiences, turning them into virtual shared social ones. This type of viewing is enjoyable but relatively unengaged with content. This is an important consideration in relation to understanding the opportunities for contextual presentation of social media against the backdrop of more traditional passive video consumption. In addition it was only through fostering social situations that live and scheduled content had continued relevance for users in terms of creating enjoyable experiences. This finding advocates the strategy of fostering socialness around content [40] as a mechanism for providing ongoing user motivation for the continued consumption of live and scheduled content as social events.

\subsection{Temporal aspects.}

The final key factor in identifying the current context was the temporal situation. Time of day and daily come-home patterns of behaviour were key to identifying the transition from shared space to quality time viewing situations. A system which can learn these patterns and identify the transition in temporal context from one to the other is feasible from established research. For an example see [43]. What was clear from this study was that later evening engaged viewing experiences are now utterly divorced from traditional concepts of television schedules or live to air content.

\subsection{A framework for differentiated design of video delivery}

Figure 6 below shows how the four archetypes discussed in section 5 can be placed within a simple framework based on the experience being solitary or shared, and taking place in a public or private space. Figure 6 also incorporates a differentiation based on time of viewing, to highlight the differences between 'sharing space but not content' and 'quality time' representing the journey into later evening engaged viewing and the effect this has on viewing behaviours. Though not the core focus of this research we also identified examples of shared social public experiences which though infrequent were rich and rewarding for participants (and would conceptually fit into the shared/public quadrant of figure 6). However, more research is needed to characterise this viewing situation more fully.

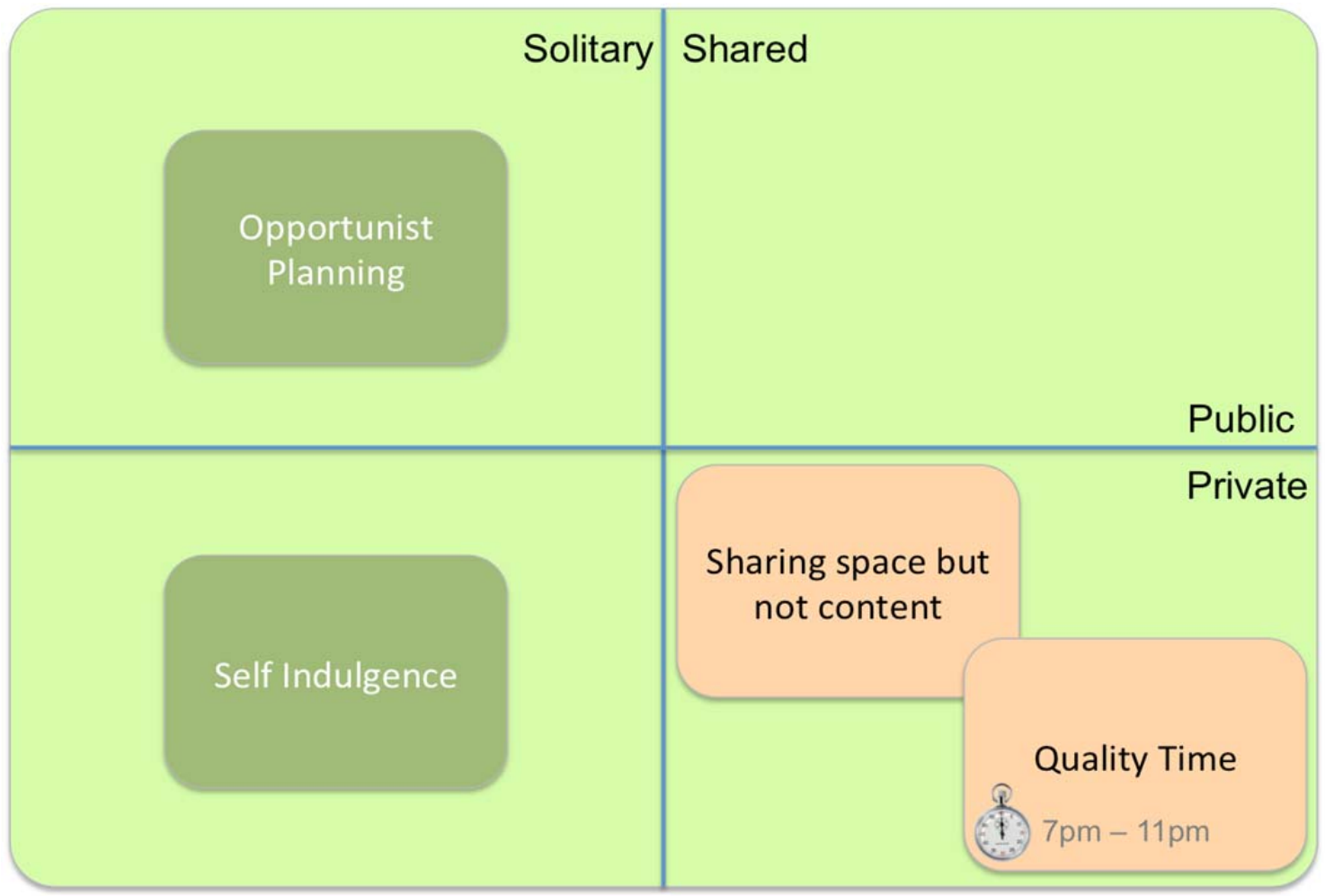

Fig. 6. A framework for differentiating key viewing situations 


\section{Conclusions}

This paper explored the key situations in which video consumption takes place and the social contexts surrounding them. They provide a rich snapshot of the settings in which future streamed video services will operate. Based on the diary study data, over two thirds of all viewing instances captured during the study fell into one of the four situations described in this paper. The presence of clear and relevant contextual cues that can be used to identify viewing situations provides an approach towards improving any type of video delivery system. In addition the findings point towards the prospect of identifying viewing situations particularly suited for the delivery of live content and related social media services - due to the content choices and major component of social interaction which makes up the current experience.

Use of qualitative methods has enabled rich data to be collected from a small sample of users. Future work may look to validate the findings through a demographically balanced quantitative survey. Additional avenues for future work will be to consider the nature of engagement and satisfaction as measurable outcomes of viewing. This can identify the impact on the user experience of watching content in the different contextual situations identified.

\section{References}

[1]. Ali, K. \& Stam, W.V., (2004). TiVo:making show recommendations using a distributed collaborative filtering architecture. In Proceedings of the tenth ACM SIGKDD international conference on Knowledge discovery and data mining. Seattle, WA, USA: ACM, pp. 394-401.

[2]. Koren, Y., (2009). The BellKor Solution to the Netflix Grand Prize, Accessed 8 Nov 2011, available at:

http://www.netflixprize.com/community/viewtopic.php?id=1537

[3]. Rohlfing, K.J., Rehm, M. \& Goecke, K.U., (2003). Situatedness: The Interplay between Context (s) and Situation. Journal of Cognition and Culture, 3(2), pp 132156.

[4]. Harrison, S. \& Dourish, P., (1996). Re-place-ing space: the roles of place and space in collaborative systems. In Boston, Massachusetts, United States: ACM, pp. 67-76.

[5]. Winograd, T., (2001). Architectures for Context. Human-Computer Interaction, 16(2, 3 \& 4), pp. 401-419.

[6]. Bellotti, V. \& Edwards, K., (2001). Intelligibility and accountability: Human considerations in context-aware systems. Human-Computer Interaction, 16(2, 3 \& 4), pp. 193-212.

[7]. Breese, J., Heckerman, D. \& Kadie,C., (1998). Empirical analysis of predictive algorithms for collaborative filtering. In: Proceedings of the 14th annual conference on uncertainty in artificial intelligence, pp. 43-52.

[8]. Ungar, L. \& Foster, D., (1998). Clustering methods for collaborative filtering. In: Proceedings of the workshop on Recommendation Systems at the 15th National Conference on Artificial Intelligence, Madison, Wisconsin. pp. 112- 128.

[9]. Bernhaupt, R., Weiss, A. \& Tscheligi, M., (2009). Users' needs, desires, and design preferences for recommendations in the living room. Multimedia Systems, Volume 15 Issue 3, July 2009. Pp. 159-171. 
[10]. Konston, J. (2001). Heavyweight applications of lightweight user models: A look at collaborative filtering recommender systems and real time personalisation. In Proceedings of the Eighth International Conference in User Modelling (UM2001), Southofen, Germany. p314.

[11]. Lekakos, K. \& Giaglis, G.M., (2006). Improving the prediction accuracy of recommendation algorithms: Approaches anchored in Human Factors. In Interacting with computers. Volume 18, Issue 3, May 2006. pp. 410-431.

[12]. Partridge, K. \& Price, B., (2009). Enhancing mobile recommender systems with activity inference. In Proceedings of the 17th International Conference in User modelling, Adaptation and Personalisation, (UMAP2009) Trento, Italy pp. 308-318

[13]. Bernhaupt, R., Obrist, M., Weiss, A., Beck, E., \& Tscheligi, M., (2008). Trends in the living room and beyond: results from ethnographic studies using creative and playful probing. ACM Comput. Entertain. 6(1), pp. 1-23.

[14]. Papper, R.A., Holmes, M.E., Popovich, M.N., \& Bloxham, M. (2005). Middletown Media Studies II: The Media Day. Muncie, In: Ball State University Center for Media Design. Accessed 5 May 2011, available at: http://www.bsu.edu/cmd/insightandresearch

[15]. O'Hara, K., Mitchell, A.S. \& Vorbau, A., (2007). Consuming video on mobile devices. In Proceedings of the SIGCHI conference on Human factors in computing systems, pp. 857-866.

[16]. Tamminen, S., Oulasvirta, A., Toiskallio, K. \& Krankainen, A., (2004). Understanding mobile contexts. Personal and Ubiquitous Computing, 8(2), pp. 135143.

[17]. Södergård, C., (2003). Mobile television-technology and user experiences, ESPOO Finland: VTT.

[18]. Miyauchi, K., Sugahara, T. \& Oda, H., (2008). Relax or Study?: A Qualitative User Study on the Usage of Mobile TV and Video. In Changing television environments. Proceedings of the $6^{\text {th }}$ European conference, EurolTV 2008. Salzburg Austria. pp 128-132.

[19]. Vorbau, W., Mitchell, A. \& O'Hara, K., (2007). "My iPod is my Pacifier": An Investigation on the Everyday Practices of Mobile Video Consumption. In HotMobile 2007. Eighth IEEE Workshop on Mobile Computing Systems and Applications pp. 29-33.

[20]. Repo, P., Hyvonen, K., Pantzar, M. \& Timinonen, P., (2004). Users inventing ways to enjoy new mobile services - the case of watching mobile videos. In Proceedings of the 37th Hawaii International Conference on Systems Science. pp. 58.

[21]. Perry, M., O'Hara, K., Sellen, A., Brown, B. \& Harper, R., (2001). Dealing with mobility: understanding access anytime, anywhere. ACM Trans. Comput.-Hum. Interact. 8(4), pp. 323-347.

[22]. Taylor, A. \& Harper, R., (2003). Switching On to Switch Off. Inside the Smart Home. Springer, London pp.115-126.

[23]. Center for research excellence, (2009). Video Consumer Mapping Study. 
Accessed 3 March 2012, available at:

http://researchexcellence.com/committees/vcm finalreport.pdf

[24]. Brown, B. \& Barkhuus, L., (2006). The television will be revolutionized: effects of PVRs and file sharing on television watching. In Montréal, Québec, Canada: ACM, pp. 663-666.

[25]. O'Brien, J., Rodden, T., Rouncefield, M. \& Hughes, J., (1999). At home with the technology: an ethnographic study of a set-top-box trial. ACM Trans. Comput.-Hum. Interact., 6(3), pp. 282-308.

[26]. Center for research excellence, (2010). Additional Data mining from VCM Study, Nielsen Consumer 360 Presentation. Accessed 3 March 2012, available at: http://www.researchexcellence.com/vcm/vcm dm 061610.pdf

[27]. Saxbe, D., Graesch, A. \& Alvik, M., (2011). Television as a Social or Solo Activity: Understanding Families' Everyday Television Viewing Patterns. In Communication Research. Volume 28, Issue 2, 2011. pp.180-189

[28]. O'Brien, J. \& Rodden, T., (1997). Interactive systems in domestic environments. In Amsterdam, The Netherlands: ACM, pp. 247-259.

[29]. Greene, J.C., (2007). Mixed Methods in Social Inquiry, John Wiley and Sons. San Francisco, CA, USA.

[30]. Silverman, D., (2001). Interpreting Qualitative Data 2nd Edition, Sage Publications, London, UK.

[31]. Taylor, A. \& Harper, R., (2002). Age-old practices in the 'new world': a study of gift-giving between teenage mobile phone users. In Minneapolis, Minnesota, USA: ACM, pp. 439-446.

[32]. Berg, B.L. \& Lawrence, B., (1998). Qualitative research methods for the social sciences, Allyn and Bacon, Boston.

[33]. Mark, G., Christensen, U. \& Shafae, M., (2001). A Methodology Using a Micro camera for Studying Mobile IT Usage and Person Mobility. In CHI Workshop on Mobile Communications: understanding users, adoption \& design, ACM CHI. Seattle, WA, USA.

[34]. Rosenthal, R., (1976). Experimenter Effects in Behavioral Research. Irvington Publishers Inc, MI, USA.

[35]. Zouinar, M., Relieu, M., Salembier, P. \& Calvet, G. (2004). Observation and capture of multimodal interaction in mobile situations. In Proceedings of the 1st French-speaking conference on Mobility and ubiquity computing. Nice, France: ACM, pp. 5-8

[36]. Christensen, U., (2001). Conventions and articulation work in a mobile workplace. ACM SIGGROUP Bulletin, 22(3), pp. 16-21.

[37]. Kirakowski, J. \& Corbett, M., (1990). Effective Methodology for the Study of $\mathrm{HCl}$, Elsevier Science Inc. New York, NY, USA.

[38]. Carroll, J., Howard, S., Vetere, F., Peck, J. \& Murphy, J., (2002). Just what do the youth of today want? Technology appropriation by young people. In System Sciences, 2002. HICSS. Proceedings of the 35th Annual Hawaii International Conference on. pp. pp.1777-1785. 
[39]. Marianna Obrist, M., Bernhaupt, R. \& Tscheligi, M., (2008). Interactive TV for the Home: An Ethnographic Study on Users' Requirements and Experiences. In International Journal of Human-Computer Interaction, 24(2) pp. 174-196.

[40]. Cesar, P. \& Geerts, D., (2011). Past, present, and future of social TV: A categorization. In Consumer Communications and Networking Conference (CCNC), 2011 IEEE, (pp. 347-351). IEEE.

[41]. Lull, J., (1990). Inside Family Viewing. Routhledge, London.

[42]. Weilenmann, A., (2003). Doing Mobility. PhD dissertation, Gothenburg. Studies in Informatics, (28).

[43]. Kappel, G., Proll, B., Retschitzegger, W., Schwinger, W. \& Hofer, T., (2001). Modelling ubiquitous web applications - a comparison of approaches. In Proceedings of the Third International Conference on Information Integration and Web-based Applications and Services (ii WAS2001), Linz, Austria. pp.163-174. 